\title{
Scientists' and science writers' experiences reporting genetic discoveries: Toward an ethic of trust in science journalism
}

Gail Geller, ScD ${ }^{1-3,}$ Barbara A. Bernhardt, $M S^{4}$, Mary Gardner, $M A^{2}$, Joann Rodgers, $M S^{5}$, and Neil A. Holtzman, $M D, M P H^{2,3}$

\begin{abstract}
Purpose: To describe the relationship between scientists and science writers and their experiences with media reporting of genetic discoveries. Methods: This study included individual interviews with 15 scientists who specialize in genetics and 22 science writers who have covered their stories and a qualitative analysis of the data. Results: Scientists and science writers place an equally high priority on accuracy of media reports. They agree on what makes genetics stories newsworthy and the particular challenges in reporting genetic discoveries (i.e., poor public understanding of genetics, the association of genetics with eugenics, and the lack of immediately apparent applications of genetic discoveries to human health). The relationship between scientists and bona fide science writers is largely positive. Scientists tend to trust, respect, and be receptive to science writers. Both scientists and science writers acknowledge that trust is an essential component of a good interview. Science writers report a fair degree of autonomy with respect to the relationship they have with their editors. Conclusion: To the degree that trust facilitates the access that science writers have to scientists, as well as higher quality interviews between scientists and science writers, trust might also contribute to higher quality media reporting. Therefore, scientists and science writers have an ethical obligation to foster trusting relationships with each other. Future research should systematically explore ways to cultivate such relationships and assess their impact on the quality of science journalism. Genet Med 2005:7(3):198-205.
\end{abstract}

Key Words: trust, media, genetics, ethics, qualitative research, science journalism

It is well established that the mass media are the greatest source of science and health information for the public. ${ }^{1}$ Equally well documented are the sins of omission and sensationalism that plague media reporting of science. ${ }^{2-10}$ Sociologists are concerned that science itself, ${ }^{11}$ as well as public perception of science, ${ }^{12}$ could be distorted by inaccurate, sensationalist, or unbalanced reporting of scientific discoveries. Some of the problems in reporting are attributed to conflicting norms of science and journalism. ${ }^{13,14}$ For example, scientists tend to consider research findings newsworthy only after they are endorsed by peers through replication, confirmation, and peer review. Journalists, however, may have less interest in findings by the time they reach this stage of review, and

From the ${ }^{1}$ Phoebe Berman Bioethics Institute, Johns Hopkins University; ${ }^{2}$ Genetics and Public Policy Studies, School of Medicine, Johns Hopkins University; ${ }^{3}$ Department of Health Policy and Management, Bloomberg School of Public Health, Johns Hopkins University; ${ }^{4}$ Department of Medicine, University of Pennsylvania School of Medicine, Philadelphia, Pennsylvania; ${ }^{5}$ Office of Communications and Public Affairs, School of Medicine, Johns Hopkins University, Baltimore, Maryland.

Gail Geller, ScD, Associate Professor, Johns Hopkins School of Medicine, 550 N. Broadway, Suite 511, Baltimore, MD 21205.

Received: May 17, 2004.

Accepted: October 23, 2004.

DOI: 10.1097/01.GIM.0000156699.78856.23 consider fresh, dramatic, and possibly tentative research findings newsworthy. ${ }^{15}$

Most of the distortion in media coverage of science, however, has been attributed to poor communication between scientists and journalists, ${ }^{9,16-19}$ particularly those who are not trained in science. Interventions and guidelines aimed at improving communication between scientists and journalists have been promulgated, ${ }^{20-23}$ but these interventions focus more on the content of communication (e.g., reducing sensationalism) than on improving the relationship between scientists and journalists. Scientists' alleged distrust or resistance to cooperating with journalists are thought to underlie the poor communication. ${ }^{19,22}$ There has been little documentation of what contributes to (or constitutes) a positive relationship between scientists and journalists ${ }^{24}$ or characterization of the communication between scientists and journalists who are experienced science writers.

The value of journalists who are experienced, skilled science writers is well recognized. In one study of scientists' and journalists' attitudes toward one another, most scientists (69\%) acknowledged that stories written by science reporters are generally positive. ${ }^{23}$ Another study demonstrated that science writers were able to make recommendations for improving the public's understanding of medical research news that were 
comparable to those proposed by the scientific community. ${ }^{25}$ These studies suggest that partnerships between experienced science writers and scientists may result in less sensationalized and more accurate and informative science reporting.

Of the many scientific topics covered in the popular press, considerable attention is paid to genetics and genetic discoveries owing, in part, to the significant accomplishments associated with the Human Genome Project. ${ }^{26}$ As is true in other areas of science reporting, there is substantial evidence that media coverage of genetics, and public reaction to such coverage, is selective, inaccurate, or unbalanced. ${ }^{26-36,36 a}$ Efforts have been made to understand scientists' and journalists' (not science writers) reactions to coverage of genetics. ${ }^{24}$ Both groups think that news organizations should assign a high priority to reports about genetics. We have demonstrated elsewhere that there is $80 \%$ agreement among science writers and scientists about which items are essential to include in a story about a genetic discovery. ${ }^{34}$ However, little is known about scientists' and science writers' perceptions of their relationship with one another or how their relationship might influence media reporting about genetic discoveries.

Because the development of a sound and respectful working relationship between scientists and science writers is likely to influence the accurate and responsible communication of scientific and technologic findings, ${ }^{37}$ and because genetic discoveries have been frequently misrepresented in the media ${ }^{38}$ (Holtzman et al., manuscript submitted, 2004), we sought to describe (1) the relationship between geneticists and science writers who cover their discoveries and (2) factors that influence the reportorial process and coverage of stories dealing with genetic discoveries. This study was part of a larger study designed to understand the factors that influence media coverage of genetic discoveries, but it has implications for media coverage of science in general. The overall study was approved by the Institutional Review Board of the Johns Hopkins School of Medicine.

\section{METHODS}

\section{Sample}

In late 1999 and early 2000, the study team generated a list of all scientists at our academic medical center who had at least one genetic discovery reported in the media within the previous year. We then sent letters to these scientists inquiring as to whether they had ever been interviewed by a science writer and, for those who had experience with science writers, whether they would be interested in participating in an interview. Sixty-seven scientists were contacted, 43 responded to the initial mailing, 28 had spoken with a science writer about their research within the past year, and 19 were chosen/eligible for interviews because their research focused on the discovery of a gene or a genetic test. We then contacted all science writers from various media who had covered the discoveries of the scientists we identified as eligible to participate in interviews.
With few exceptions, the stories about the discoveries followed promptly on their publication in the peer-reviewed science literature.

\section{Procedures}

Written informed consent was obtained from those individuals who expressed interest in being interviewed. Subsequently, 1-hour interviews were conducted by one of the coinvestigators. The coinvestigators with science backgrounds conducted the interviews with scientists. The coinvestigator with a social science background conducted the interviews with science writers. All scientist interviews and most interviews with science writers were conducted in person. Interviews with a few of the science writers were conducted by phone because of geographic distance. With the permission of the subjects, the interviews were audiotaped. No incentives were offered. The interviews of science writers also included a one-page survey in which they recorded the extent of their training in science and whether they were members of the $\mathrm{Na}$ tional Association of Science Writers (NASW).

The interviews were semistructured. We constructed parallel interview guides for scientists and science writers that included some questions specific to genetics: (1) what makes a genetics story newsworthy and is there something particular about genetic discoveries relative to other science reporting with respect to their newsworthiness; (2) what, if any, are the particular challenges in reporting on genetic discoveries; (3) what do they think the media's role is in reporting on genetics or genetic discoveries. Other items focused on the reportorial process in general: (4) scientists' perceptions of journalists and science writers' perceptions of scientists, their respective goals in communicating, and how accessible they are to each other; (5) what characterizes a good/bad interview; (6) how science writers feel about disclosing conflicts of interest in science and factors that influence such disclosure; (7) how scientists feel about being critical of other scientists; and (8) to what degree science writers have freedom with respect to their editors. In the interviews with scientists, these process-oriented questions referred to journalists or reporters in general, not science writers. Only when the scientist raised the distinction themselves did we pursue it with them.

\section{Data analysis}

After review of a subset of the initial interview transcripts by the investigators to identify themes, a codebook was developed through an iterative process of transcript review and refinement of subcodes and definitions. Two coders (the project coordinator and a research assistant) double-coded sets of transcripts and refined code definitions until intercoder reliability of over $80 \%$ was achieved. The remaining interviews were coded by the research assistant, then reviewed by the project coordinator for completeness and accuracy of coding. Once all transcript codes had been entered in NUDIST software for qualitative data analysis, text reports were produced. 


\section{RESULTS}

\section{Respondents and response rates}

Of the 19 scientists who were eligible to participate, 15 were interviewed (79\% participation). Two of the 15 scientists were women. Of the 23 science writers who were eligible and contacted, 22 were interviewed (96\% participation). Seven of the science writers were women $(32 \%)$ and 15 were men $(68 \%)$. Eleven $(50 \%)$ covered science for major newspapers, 5 for magazines, 2 for television, 2 for the Internet, 1 for radio, and 1 for a major news wire service. Reporters came from geographically diverse regions of the country. Among the science writers, $63 \%$ had formal training in science. Of these $14,60 \%$ were members of NASW.

\section{Perceptions of the "newsworthiness" of genetic discoveries}

Both scientists (S) and science writers (SW) agreed that newsworthy stories were those that were novel, applicable, controversial, credible, and entertaining. Although science writers assigned a higher priority than scientists to novelty and entertainment, they acknowledged that what constitutes novelty changes over time, particularly for genetics stories.

"Genetic theory and genetic research has a long history, and a controversial history, so there is just a great deal of fascination with the subject to start with without any discoveries coming along. Meanwhile, the pace of the discoveries has really picked up and the number of players involved has increased. There are now new sorts of complex rivalries developing." SW-10

". . .the gene diagnostic test of the day is no longer newsworthy. The possible, hopeful, maybe treatment. . based on a mouse or other rodent study is not newsworthy. To me, it's how does it affect a person's life today. .."; SW-4

Therefore, today's newsworthy discoveries must relate to common diseases, to some immediate therapeutic application, or involve some controversy.

\section{Are there any particular challenges in reporting on genetic discoveries?}

The challenges and concerns in reporting on genetic discoveries are quite similar for scientists and science writers. The challenges relate to poor public understanding of genetics, the association of genetics with eugenics, and the lack of immediately apparent applications of genetic discoveries to human health.

"When people think about genetic testing, a lot of people think about eugenics and, for people with undesirable traits, concerns about insurance, employability, and privacy." S-16

". . .the public is very naïve about the details of genetics and when they see Mendelian versus non-Mendelian, you may ask anybody on the street and they will say, 'Huh?'. .."; S-48

"One challenge is, when is it news? Is it news when a gene for some disease is localized to a chromosome? Is it news when it's localized to this many megabases as opposed to that many megabases?" SW-17
". . .genetic stories have to have a somewhat higher threshold. They're quite difficult to explain. . .so they have to have...more news impact, say, than the sort of medical or human interest story." SW-20

Although scientists may not be as interested in finding a new story angle, they otherwise share science writers' appreciation for the difficulties of communicating genetic discoveries to the public.

\section{Perceptions of the media's role}

Education was the role mentioned most frequently by scientists. Science writers stressed that their major role as a science writer is to inform, not to educate, the public.

"Whenever people talk about the media's role in educating the public, I get a little worried. . .It seems to me that [our] role is to report the news. . .beyond that, I'm not sure it's our job." SW-17

"There are a lot of folks in this building or members of the Association who think our job is education. I don't think that's the way we interpret it in the news section. We try to be neutral on issues." SW-10

However, with respect to genetics, many science writers reported that they need to take on a larger role in educating the public, and several science writers remarked that it is difficult to write about genetics without some degree of education, not only about genetic concepts, but about ethical issues relating to genetics and genetic testing.

"When you're writing about genetic subjects you have to give some kind of background or education about terms that you're using, whereas I don't think that would be so necessary if you were writing about obesity or cancer. . . think there's also some sort of consumer advocate function in trying to warn people about the possible risks of undergoing genetic testing or risks of a genetic technology that you're writing about." SW-18

"I think the one thing that the press has done very well is to sort of up the consciousness of genetics. . . remember having to define DNA. I had it on a macro key that you would just plug in every time you wrote about it. . .And now you don't have to do that anymore. . But every time you define a term you're educating." SW-35

By and large, participants thought it was particularly important to educate readers about the limitations and risks of genetic testing and thought they had accomplished this goal.

\section{Interactions with each other}

Scientists indicated that most of the journalists they interacted with were well-informed about science in general and genetics in particular. There was a sense that scientists have greater faith in journalists who are trained in science.

"I think there are a lot of outstanding medical writers. . .in part because they're reasonably knowledgeable about the subject matter, but also about the way science works. So they don't require a lot of being brought up to speed first. And second, they don't ask naïve things. . "; S-78 
"I think that if you're speaking to a scientific science writer, you [can] assume that many things are understood, and not have to explain..."; S-32

Several of the scientist-respondents thought that science writers were not usually the ones responsible for inaccuracies in reporting. Instead, scientists tended to attribute inaccuracies to the scientists themselves. Scientists seemed to appreciate that the culture is different for science writers than for scientists, often centering on differences in time demands. However, scientists believe that reconciliation of these differences is desirable and achievable.

The majority of the scientists we interviewed were receptive to talking to the press, and science writers acknowledge that access to scientists has improved over time.

"I think in general the academic world and scientists have gotten more sophisticated about the need to communicate, even in what appear to be adverse situations." SW-10

"It's gotten a lot easier to get people to talk to you than it used to be." SW-23

Where scientists indicated being selective about which journalists they would communicate with, factors such as time limitations or the quality of the publication were mentioned, rather than a general dislike or avoidance of the press.

When scientists were asked why they talk to the press, their responses centered around two major goals. The primary goal was to inform the public about their work and to do so accurately. In this way, they could help to de-stigmatize illness, increase awareness that would lead to greater public health, and provide an historical context for their work. Some scientists implied that the better the scientist, the greater his/her duty to talk to the press:

“. . . if the best scientists didn't talk to the news media because it is unseemly, and other scientists look down on some of us that speak to the news media, then guess which kinds of scientists will do all of the talking to the media-mainly the charlatans, and then we really will have trouble." S- 48

Scientists also expressed secondary goals of talking to reporters that focused on improving public relations, institutional prestige, and funding. They thought that media reports could facilitate recruitment to specific genetic studies or encourage general public participation in trials, testing or treatment protocols, and inform the public about how tax dollars are spent.

The two main reasons that scientists gave for being reluctant to talk to the press had more to do with their own fears than with negative judgments about journalists. Their fears related to a lack of confidence in their ability to express themselves and their work, and what their colleagues would think of them.

"... In general, the biggest problem among scientists is that they tend not to be very articulate and even if they could be articulate, they are afraid of not saying what they really think and just talking about research because their peers will look on them with derogation that they are just, you know, not serious scientists." S-48

When science writers were asked the parallel question of why they talk to scientists, they also expressed two primary goals. The first was to make sure they had a full understanding of what the science involved.

"...we talk to the authors of studies for the purpose of fleshing out what's in the story. . . and checking points, and making sure that we're accurately portraying what the study has said." SW-18

The second goal was to establish a relationship with the primary author not only because he/she is an established authority in the field but because they would have easier access to the scientist in the future:

"Once you have already interviewed someone, you tend to go back to them... [if] you've established a relationship with them, you can call them and they know you; they trust you... some people you call up, if they don't have experience talking to you, they get a little flustered. So if you know the person, it makes it easy. .."; SW-1

Several science writers acknowledged that, as a result of a trusting relationship, they have greater opportunity to explore sensitive or controversial issues including ethical dimensions and limitations of the science.

\section{Perceptions about what makes a good/bad interview}

Both scientists and science writers agree on what makes a good/bad interview. Bad interviews are characterized by the absence of trusting, collaborative partnerships.

"A bad one is an interview with somebody who doesn't trust you. . .who assumes that you're going to get it wrong, or that you're going to hype it or that, you know, all journalists are out to sell newspapers." SW-1

"A bad interview is somebody who is misleading. . .sometimes people will say something, and you look at their paper and you say, that's not what it meant. . .Now that's a bad interview because I shouldn't have to rely on my own ability to pick up discrepancies. I should count on them to be honest with me." SW-8

"Well, I think it's more just a feeling that you are not really communicating very well and that they are not really listening to what you are saying. .."; S-24

"...there needs to be an essential rapport and trust from the beginning. And then once that's established, things automatically tend to go well." SW-23

For scientists, trusting relationships are facilitated by adequate knowledge of science and good interviewing skills on the part of the science writers.

"It was very easy to talk to her. She had, I thought, a terrific grasp of science, in general. And she really listened when I would speak." S-16

For science writers, good interviews are facilitated by the scientist's ability to articulate clearly, but they acknowledge their own responsibility with respect to adequate preparation and personal interview style.

"I try to give them the respect of having made a real effort to understand their research. And I try to convey my knowledge of science very early on so they feel comfortable... It's very important that you be interested in the subject and convey that 
interest. . .And so that starts something going, so that it's more of a conversation than it is just a fact-finding mission." SW-1

"I might tell them that I've covered some things in this field before, or that I'm familiar with things related to this work, so that they'll see that, you know, I haven't just been thinking about this in the last fifteen minutes." SW-18

\section{Science writers' attitudes about disclosure of conflicts of interest}

Most of the science writers said they try to ask about conflicts of interest during an interview, or investigate them before an interview, but often such information is not included in the story. They believe that some degree of conflict of interest is to be expected but such conflicts are included in stories only if they are highly significant and if there is sufficient space.

"To include a conflict of interest in a story, it has to be big and it has to be meaningful in some sense." SW-3

"I don't include the fact that, you know, this research was supported by an NIH grant, an NSF grant; but if there's a pharmaceutical involvement, then yes, that would be included." SW-1

"... .there's so many other bits of information that are clamoring for a limited amount of space for the story, that often I will leave out the financial interest." SW-20

"I think it's almost inevitable that there is some tainting...but I have found that people's bias is much more the result of ideology than it is financial." SW-32

\section{Scientists' willingness to critique the work of their peers}

Scientists are reluctant to be critical of other scientists or to say anything negative about the work of other scientists when they are interviewed by science writers, even those they trust. Science writers seem to be aware of and sensitive to scientists' interests in being careful about critiquing colleagues (see Table 1). Therefore, obtaining expert opinions from scientists who are uninvolved with a particular discovery may be especially challenging and require certain skills on the part of science writers.

\section{Science writers' editorial freedom/autonomy}

The science writers we interviewed, by and large, experienced considerable freedom regarding both the stories they choose to publish and the content of those stories.
“I've never had a story that wasn't published. I can't imagine. . by the time you are an experienced writer and you and your editor agree that something should be covered, it's going to be published" SW-8

"I'm pretty much left to my own devices to find the news here. The vast majority of the stories that I write are ones that I found which I think is wonderful. . .How heavily am I edited? It depends on the story but it's eighty to ninety percent what I wrote the first time." SW-17

"The relationship between the final story and what I first wrote depends on the story. In most cases, it's fairly similar, especially if it's a sort of breaking daily story. . . the editors here will often be persuaded by what the reporter says." SW-18

Therefore, science writers seem to have a fair degree of autonomy with respect to the relationship they have with their editors.

\section{DISCUSSION}

Despite the prevailing view that scientists and journalists are adversaries, our findings suggest that the nature of the relationship between scientists and science writers is positive. The scientists in this study tend to be receptive to the press. The science writers acknowledge scientists' growing receptivity, and they report greater ease in gaining access to scientists.

The positive relationship between scientists and science writers in this study may be attributable, in part, to the shared value that both groups place on accuracy of reporting. Similar values and their positive impact on communication between scientists and science writers has been observed elsewhere. ${ }^{24}$ However, we did observe some disagreement about the intention or role of the media in covering science news. Almost all of the science writers we interviewed said that they write primarily to inform and secondarily to educate, whereas the majority of scientists thought the primary role of the media should be to educate. This confirms earlier studies. ${ }^{15,18}$ However, several science writers acknowledged that if they could educate and inform simultaneously that would be even better. In fact, many of the science writers we interviewed believed that genetics stories, in particular, require a certain degree of education because of their complexity. Not surprisingly, we have demon-

Table 1

Scientists' willingness to critique the work of their peers: Concordance between respondents

Scientists
"If you can be wholeheartedly positive. . .this is fine. If you have some
critical comments, you have to very carefully couch them." S-1
"If the only thing I had to say was negative, I would decline the
interview." S-10
"I try to be as upbeat as possible. I don't remember any instance where I
trounced on the work as being irresponsible or inaccurate." S-77
"Other scientists do not like to see [those] things in the newspaper. It
causes a tremendous amount of professional rivalry. . .It can make it
difficult to interact with your peers and it sets you up as a target." S-53

"[Scientists] will give lukewarm praise sometimes, which fairly clearly overlies some. . .negative feelings that they don't really want to say." SW-18

"Criticizing colleagues' work is difficult. And often they. . .insist on being off the record. But, I mean, scientists are trained to be skeptical. . .So, they definitely will have criticisms or reservations which you can usually get them to express." SW-20 
strated elsewhere that science writers (as measured by NASW membership) produce reports of genetic discoveries that are more comprehensive and balanced than stories written by journalists who are less likely to have a science background or a special interest in science. ${ }^{36 a}$

Another theme that emerged from most of our interviews was trust and its role in the relationship between scientists and science writers. Our results indicate that scientists, at least those whose primary interest is genetics, tend to respect and trust science writers. Such trust may contribute to the greater access that science writers reportedly have to scientists. Evidence exists that access to well-informed experts is critical to the thorough investigation of the merits and deficiencies of a given scientific report. ${ }^{39}$ Science writers, for their part, express an explicit interest in cultivating relationships with scientists. Both scientists and science writers acknowledge that trust is an essential component of a good interview. Through its impact on facilitating science writers' access to scientists, and improving the interview itself, trust might also contribute to higher quality media reports.

One of the ways in which science coverage could benefit from trusting relationships between scientists and science writers is that each party might be more comfortable disclosing his or her insecurities to the other. According to Hartz and Chappell's 1997 survey, ${ }^{19}$ most science writers expressed insecurities about their own abilities and performance. Scientists expressed fears about being embarrassed before their peers. In the context of a trusting relationship with a science writer, scientists might feel safe enough to acknowledge ongoing controversies or tensions they may have with particular colleagues or identify the circumstances under which their fears are most likely to arise. Likewise, science writers might feel secure enough to raise certain sensitive topics that might affect the quality of reporting.

Two areas where scientists and science writers might benefit from a trusting relationship involve the use of expert opinions and the existence and nature of any conflicts of interest. We have demonstrated elsewhere that science writers assign a higher priority than scientists to including outside opinions and reporting financial interests and implications of discoveries, ${ }^{34}$ but their actual stories seldom report outside opinions or financial interests. ${ }^{36 \mathrm{a}}$ How are science writers able to elicit outside opinions from scientists in light of our evidence that scientists are reluctant to critique the work of their peers? And why do science writers admit to frequently omitting conflicts of interest from their stories? We speculate that trust may play a role in reconciling the discrepancy between saying that these topics are essential to report on the one hand, and the low likelihood of actually including them in media reports on the other. In a trusting relationship, scientists might be more willing to respond to evaluative questions about the work of their peers, and science writers might ask for and be given suggestions about which other expert opinions to seek in order to provide the appropriate balance to the story. Failure of scientists to criticize the work of other scientists might also be a function of mistrust among scientists.
Because the perceived accuracy and reliability of scientific news is usually linked to the perceived credibility of the source, ${ }^{37}$ disclosures of conflicts of interest and other sorts of biases also can contribute to balanced reporting. Although some have argued that including disclosures of conflicts and biases could impede scientific progress and erode public trust in the scientific enterprise, ${ }^{5,40}$ there is considerable agreement that to enable audiences to evaluate the credibility of scientists' arguments, journalists should investigate and disclose values that could influence the science. ${ }^{9,41}$ The science writers we interviewed say they report such conflicts if they are significant enough and if there is sufficient space. Moreover, some agree that subtle biases are often more significant than overt financial conflicts of interest, an observation that is supported in the literature. ${ }^{5}$ In a trusting relationship with a scientist, a science writer might be able to clarify whether a particular conflict is important to disclose or not. Without feeling free to ask scientists about the nature of their conflicts, and without being able to expect an honest answer, science writers may never appreciate the nuances of such conflicts. Furthermore, to the degree that science writers have greater autonomy with respect to their editors, they may be able to command more space or succeed in retaining information about conflicts of interest. Therefore, science writers who have cultivated trusting relationships with scientists (and with their editors) may be in a better position to report conflicts of interest.

Science writers must also be careful to earn the trust of scientists by not misusing the information that is disclosed. ${ }^{42}$ There are times when a science writer may want to report a conflict of interest that the scientist thinks is unimportant. In such cases, the science writer may function as mediator between the interests of the scientist and the interests of the public. Being able to negotiate this balance in the context of a trusting relationship might allow for the disclosure of the conflict of interest without losing the scientists' trust.

\section{Limitations}

Although the response rate of both groups was very high and, among science writers, various media were represented, this study has several limitations. First, our findings may not be generalizable, because qualitative interviews are not intended to produce representative findings. Not only was the sample size small, but the participant recruitment processes may have reinforced sample/selection bias. For example, all scientists came from one institution and had some experience interacting with the media. All journalists were experienced science writers who had covered genetics and all came from organizations with more resources than the average newspaper or local television station. Furthermore, participants were more likely to have had some rapport with one another because we interviewed reporters who had covered the discoveries of these scientists. Finally, the relationship between these highly experienced science writers and their editors may not be the same as that between less experienced science journalists and their editors. Therefore, perspectives from a broader sample will be necessary to know whether the observations we made are rel- 
evant to scientists and science writers beyond those we interviewed.

\section{An ethical obligation to promote trust}

Despite these limitations, our findings suggest that trust is an important component of the relationship between scientists and science writers. Even though the development of trusting relationships will not mitigate all of the sources of tension between scientists and science writers, cultivating such relationships, now and in the future, may contribute either directly or indirectly to higher quality media coverage of science in general, and genetics in particular. As a result, we believe that scientists have an ethical obligation to foster trusting relationships with science writers, and journalists who want to cover science news have an ethical obligation to be knowledgeable about science and trustworthy. Because one of science writers' primary motivations in communicating with scientists is to establish a relationship with them, science writers may be wellpoised to set the example for scientists with respect to the development of trusting relationships. Moreover, scientists in the field of genetics may offer a model for a successful partnership in which to test the impact of such relationships. Geneticists may find it fairly easy to develop trusting relationships with science writers because many science writers appear to share geneticists' views about what makes a genetics story newsworthy and what ought to be included in a genetics story. ${ }^{34}$

However, it is not known whether higher quality media reports would translate into greater trust in both science and the media among the general public. Much has been written about trust in the context of biomedical research ${ }^{43-45}$ public trust in the health care system overall, ${ }^{46}$ and public trust in the media. ${ }^{47}$ In this study, we present the first empirical evidence of the potential role of trust in the relationship between scientists and science writers. Future research should seek to understand the nature and impact of trust among scientists and the elements of a trusting environment for scientists and science writers, systematically explore ways to cultivate or facilitate trusting relationships between science reporters and scientists and among scientists, and assess the impact of such relationships on the quality of, and public trust in, media coverage of science.

\section{ACKNOWLEDGMENTS}

This study was supported by a grant (R01 HG01871-03S1: Publicizing Genetic Discoveries: The Impact of the Media) from the National Human Genome Research Institute. We wish to thank the scientists and science writers who participated in the interviews. We also appreciate the contributions of Ellen Tambor, who coordinated the overall study, and Eliza Mountcastle-Shah, who conducted some of the scientist interviews.

\section{References}

1. Roper Starch Worldwide, Inc. Americans talk about science and medical news. The National Health Council Report, 1997.

2. Altman LK. Promises of miracles: News releases go where journals fear to tread. New York Times January 10, 1005:C3.
3. Dowie M. What's wrong with the New York Times's science reporting? The Nation July 6, 1998:13-19.

4. Koren G, Klein N. Bias against negative studies in newspaper reports of medical research. JAMA 1991;266:1824-1826.

5. McComas KA, Simone LM. Media coverage of conflicts of interest in science. Sci Commun 2003;24:395-419.

6. Moynihan R. Making medical journalism healthier. Lancet 2003;361:2097-2098.

7. Pellechia MG. Trends in science coverage: A content analysis of three U.S. newspapers. Public Underst Sci 1997;6:49-68.

8. Ransohoff DF, Ransohoff RM. Sensationalism in the media: When scientists and science writers may be complicit collaborators. Eff Clin Pract 2001;4:185-188.

9. Shuchman M, Wilkes MS. Medical scientists and health news reporting: A case of miscommunication. Ann Intern Med 1997;126:976-982.

10. Singer E. A question of accuracy: How science writers and scientists report research on hazards. J Commun 1990;40:102-116.

11. Durant J, Hanson A. The role of the media. In: Kennet WK, editor. Parliaments and Screening: Ethical Issues Arising from Testing for HIV and Genetic Disease. Paris: John Libby Eurotext, 1995.

12. Nelkin D, Lindee S. The DNA mystique: The gene as cultural icon. New York: WH Freeman, 1995.

13. Franklin J. Scientific inquiry: The forces shaping science journalism. Currents 2002; 28:24-26.

14. Highfield R. Selling science to the public. Science 2000;289:59.

15. Nelkin D. An uneasy relationship: The tensions between medicine and the media. Lancet 1996;347:1600-1603.

16. Hargreaves N, Ferguson G. Who is misunderstanding whom? Bridging the gulf of understanding between the public, the media and science. Bristol, England: Economic \& Social Research Council, 2000.

17. Johnson T. Shattuck lecture: medicine and the media. N Engl J Med 1998;339:87-92.

18. Peters HP. The interaction of science writers and scientific experts: Cooperation and conflict between two professional cultures. Media, Culture \& Society 1995;17:31-48.

19. Hartz J, Chappell R. Worlds Apart: How the Distance Between Science and Journalism Threatens America's Future. Nashville: First Amendment Center, 1997.

20. Ficklen E. Science lessons: The good, the bad, and the ugly of communicating research. Currents 2002;28:16-23.

21. Owens SR. It's good to talk: Media training workshops are aiming to break down the barriers between scientists and science writers. EMBO Reports 2002;3:709-711.

22. Rensberger B. Why scientists should cooperate with science writers. Sci Eng Ethics 2000;6:549-552.

23. Stamm K, Williams JW, Hitchcock-Noel P, Rubin R. Helping science writers get it right: A physician's guide to improving health care reporting. J Gen Intern Med 2003;18:138-145.

24. Valenti JM. Improving the scientist/science writer conversation. Sci Eng Ethics 2000 6:543-548.

25. Cooper CP, Yukimura D. Science writers' reactions to a medical "breakthrough" story. Soc Sci Med 2002;54:1887-1896.

26. Tambor ES, Bernhardt BA, Rodgers J, Holtzman NA, Geller G. Mapping the human genome: An assessment of media coverage and public reaction. Genet Med 2002;4: $31-36$.

27. Condit CM, Achter PJ, Lauer I, Sefcovic E. The changing meanings of "mutation": A contextualized study of public discourse. Hum Mutat 2002;19:69-75.

28. Conrad P. Genetic optimism: Framing genes and mental illness in the news. Cult Med Psychiatry 2001;25:225-247.

29. Conrad P, Gabe J. Introduction: Sociological perspectives on the new genetics: An overview. Sociol Health Illn 1999;21:505-516.

30. Durant J, Hanson A., Bauer M. Public understanding of the new genetics. In: Marteau T, Richards M, editors. The Troubled Helix: Social and Psychological Implications of the New Human Genetics. Cambridge: Cambridge University Press, 1996.

31. Geller G, Bernhardt BA, Holtzman NA. The media and public reaction to genetic research. JAMA 2002;287:773.

32. Geller G, Tambor ES, Bernhardt BA, Rodgers J, Holtzman NA. Houseofficers' reactions to media coverage about the sequencing of the human genome. Soc Sci Med 2003;56:2211-2220.

33. Kerr A, Cunningham-Burley S, Amos A. The new genetics: Professionals' discursive boundaries. Sociological Review 1997;45:279-303.

34. Mountcastle-Shah E, Tambor E, Bernhardt BA, Geller G, Karaliukas R, Rodgers J, Holtzman NA. Assessing mass media reporting of disease-related genetic discoveries: Development of an instrument and initial findings. Sci Commun 2003;24:458 478

35. Petersen A. Biofantasies: Genetics and medicine in the print news media. Soc Sci Med 2001;52:1255-1268.

36. Stockdale A. Public understanding of genetics and Alzheimer's disease. Genet Test 1999;3:139-145. 
36a. Holtzman NA, Bernhardt BA, Mountcastle-Shah, et al. The quality of media reports of discoveries related to human genetic diseases. Community Genetics 2005 (in press).

37. Garrett JM, Bird SW. Ethical issues in communicating science. Sci Eng Ethics 2000; 6:435-442.

38. Bubela TM, Caulfield TA. Do the print media "hype" genetic research? A comparison of newspaper stories and peer-reviewed research papers. CMAJ 2004;170:1399-1407.

39. Lantz JC, Lanier WL. Observations from the Mayo Clinic National Conference on medicine and the media. Mayo Clin Proc 2002;77:1306-1311.

40. Cohen JJ. Trust us to make a difference: Ensuring public confidence in the integrity of clinical research. Acad Med 2001;76:209-214.

41. Boffey PM, Rodgers JE, Schneider SH. Interpreting uncertainty: A panel discussion. In: Friedman SM, Dunwoody S, Rogers CL, editors. Communicating Uncertainty:
Media Coverage of New and Controversial Science. Mahwah, NJ: Lawrence Erlbaum, 1999.

42. Holmes DR, Firth BG, James A, Winslow R, Hodgson PK, Gamble GL et al. Conflict of interest. Am Heart J 2004;147:228-237.

43. Kass NE, Sugarman J, Faden R, Schoch-Spana M. Trust: The fragile foundation of contemporary biomedical research. Hastings Cent Rep 1996;26:25-29.

44. Yarborough M, Sharp RR. Restoring and preserving trust in biomedical research. Acad Med 2002;77:8-14.

45. DeAngelis CD. Conflict of interest and the public trust. JAMA 2000;284:22372238.

46. Hall MA, Camacho F, Dugan E, Balkrishnan R. Trust in the medical profession: Conceptual and measurement issues. Health Serv Res 2002;37:1419-1439.

47. Wilkie T. Sources in science: Who can we trust? Lancet 1996;347:1308-1311. 